Stoker, M. G. P., Sмith, K. M. \& Fiset, P. (1956). J. gen. Microbiol. 15, 632-635

\title{
Internal Structure of Rickettsia burnetii as shown by Electron Microscopy of Thin Sections
}

\author{
By M. G. P. STOKER, K. M. SMITH AND P. FISET \\ Department of Pathology, University of Cambridge, and the Agricultural Research \\ Council Virus Research Unit, Cambridge
}

SUMMARY: Thin sections of purified suspensions of Rickettsia burnetii were examined by electron microscopy. The organism possesses a limiting membrane, within which lie a granular region and a dense central body. The configuration of the central body suggests that it may consist of an elongated and irregularly twisted strand.

The development of techniques for examining thin sections by electron microscopy has led to studies on the internal structure of several bacteria and viruses. Sections of bacteria show them to be almost filled with dense granular or sponge-like material closely surrounded by a limiting membrane, but with less dense 'vacuoles' in the centre which contain small threads and elongated bodies thought to correspond to a nuclear apparatus (see Chapman \& Hillier, 1953; Kellenberger \& Ryter, 1955; Bradfield, 1956; Maaløe \& Birch-Andersen, 1956). Animal viruses have been examined in thin sections of infected tissue. Vaccinia and fowl-pox viruses are oval with a single or double limiting membrane and an eccentrically placed inner body (Gaylord \& Melnick, 1953; Morgan, Ellison, Rose \& Moore 1954 $b$ ); herpes virus is round or oval with a central body and one or two membranes probably depending upon the stage of development and the position in the cell (Morgan, Ellison, Rose \& Moore 1954 $a$ ); elementary bodies of meningo-pneumonitis virus are dense with central granules, but large circles with no internal granules are also seen in sections of infected tissue (Gaylord, 1954).

The rickettsias are commonly regarded as intermediate between bacteria and the larger animal viruses. Their size, staining properties and metabolic activity link them to the bacteria, but, like viruses, they remain dependent upon living cells for growth. It is therefore of some interest to know how their fine structure resembles those of the viruses and bacteria. Electron microscopy of intact rickettsias has confirmed that they are rod-shaped organisms, about $300 \mathrm{~m} \mu$. in diameter, and varying from $500 \mathrm{~m} \mu$. to at least $1000 \mathrm{~m} \mu$. in length. A limiting membrane may be seen and this is separated from an electron dense central portion which in shadowed preparations shows a convoluted irregular surface and remains elevated above the supporting membrane (Stoker, 1950); but the internal structure cannot be clearly seen when the whole organism is examined in this way. In the studies to be described in this paper the internal structure of Rickettsia burnetii was examined by electron microscopy of ultrathin sections. 


\title{
Internal structure of Rickettsia burnetii
}

\section{METHODS}

\author{
Preparation of suspension of Rickettsia burnetii
}

Preparations were made from infected yolk sacs of the second egg passage of a guinea-pig-adapted line of the Nine Mile strain of Rickettsia burnetii. The harvested yolk sacs were stored at $-20^{\circ}$ until used. The purified suspension of rickettsias was made from the infected yolk sacs by ether extraction and differential centrifugation, as for preparation of antigen (Stoker, 1953). This method normally involves treatment with formalin but in the electron microscope preparations osmic acid fixation gave better results, and so formalin was excluded from all suspending media during purification and storage. Judging by electron microscopy, the final preparations were almost completely free from extraneous material. They were stored at $4^{\circ}$ in phosphate buffered saline up to 2 weeks before fixation and embedding.

\section{Sectioning technique}

The purified suspensions were centrifuged at 8000 r.p.m. for $30 \mathrm{~min}$. and fixed by resuspension in $2 \%$ osmic acid in citrate phosphate buffer for $2 \mathrm{hr}$. The fixed rickettsias were then recentrifuged, and the pellet was dehydrated with ethanol in $10 \%$ steps. It was embedded in a mixture of 4 parts $n$-butyl methacrylate and 1 part methyl methacrylate. The sections were not shadowed with metal since the methacrylate was not removed, and they were cut on a Cook and Perkins microtome fitted with a glass knife. Some of the electron micrographs were taken on a Siemens-Elmiskop I microscope at $80 \mathrm{kV}$., and the others on a Metropolitan Vickers EM 3 electron microscope at $75 \mathrm{kV}$. Those sections which were thin enough were photographed at a magnification of $\times 40,000$ on the Siemens microscope and later enlarged optically. Either carbon or formvar supporting films were used in the grids.

\section{RESULTS}

Electron micrographs of the sections of the osmic acid fixed rickettsias are shown in Pls. 1 and 2. The organisms were fairly closely packed, and differed in orientation in various parts of the pellet, so that in some places they were sectioned longitudinally (Pl. 1, fig. 1) and, in others almost transversely (Pl. 1, fig. 2; Pl. 2, fig. 3).

The size of the rickettsias cannot be estimated accurately because of the different planes and angles of section. Assuming that circular sections are transverse, however, it is of some interest that the largest of these sections (which are presumably not at the extremities), show a diameter of less than $200 \mathrm{~m} \mu$. Even allowing for shrinkage in the methacrylate this is considerably smaller than the diameter usually found by conventional electron microscopy of intact organisms, and suggests that the latter have flattened and spread during settling and drying on a surface.

All the organisms showed a distinct limiting membrane of finely granular material 5-10 $\mathrm{m} \mu$. in thickness. The limiting membranes of some of the 
rickettsias are fractured but many appear to be intact. Inside the membrane was a clearly defined intermediate zone of moderately dense material surrounding a very dense irregular central body (Pl. 2, fig. 4).

The intermediate zone was somewhat separated from the outer limiting membrane, or its density diminished as it approached the membrane. When not cut obliquely this intermediate zone was about $25 \mathrm{~m} \mu$. in thickness and contained granules of about $5 \mathrm{~m} \mu$. in diameter. The density of the region appears to be less than that of the main granular region of sectioned bacteria, but the granules themselves were of similar size.

Within the intermediate granular region of the rickettsias was a 'hole' in which lay a very dense central body. The latter was seen in most sections of the organisms and presumably therefore extended through a large part of the length of each. The configuration of this central body varied greatly in different organisms. In many it was large, circular and apparently hollow, in some small circular and solid, and in others comma shaped or sigmoid. One, or possibly two, irregularly twisted strands appeared to give rise to this appearance, but serial sections would be needed for confirmation. Pl. 2, fig. 5, however, shows a single rickettsia sectioned longitudinally and in which the central body appears to be a single elongated strand twisted and doubled back on itself.

\section{DISCUSSION}

From the sections it appears that Rickettsia burnetii has a limiting membrane and an intermediate zone of granular material resembling that of many bacteria which have been examined (compare, for example, sections of Escherichia coli by Birch-Andersen, Maaløe \& Sjöstrand, 1953). There is also a space containing a central body. In the rickettsia, however, the intermediate granular region is far less dense than in bacteria and probably occupies a small proportion of the volume of the organism, while the central body of the rickettsia, on the other hand, is very dense, clearly defined, and proportionately large, compared with the bodies seen in the central region of bacteria.

By using a modified Feulgen reaction Bradfield (1954) showed that the deoxyribonucleic acid of staphylococci and paracolon bacilli was situated in the region of the central vacuole. No such studies have been made on Rickettsia burnetii, but it is known that the organism has a relatively high content of deoxyribonucleic acid as compared with bacteria (Smith \& Stoker, 1951) and it is possible that this is associated with the prominent central body. It would be interesting to know whether the relatively sparse granular region of the rickettsia is in any way connected with their low content of ribosenucleic acid, and, in turn, with the presumed lack of ability of rickettsias to synthesize protein. As may be expected, the structure of the rickettsias in purified suspensions is less variable than that of viruses in the sections of infected tissues showing various stages of development (Morgan et al. 1954a, b). Nevertheless, sections of vaccinia and herpes viruses show, on a small scale, some particles with a central body and a double membrane not unlike transverse sections of $\boldsymbol{R}$. burnetii. 
Journal of General Microbiolog!y, Vol. 15, No. 3
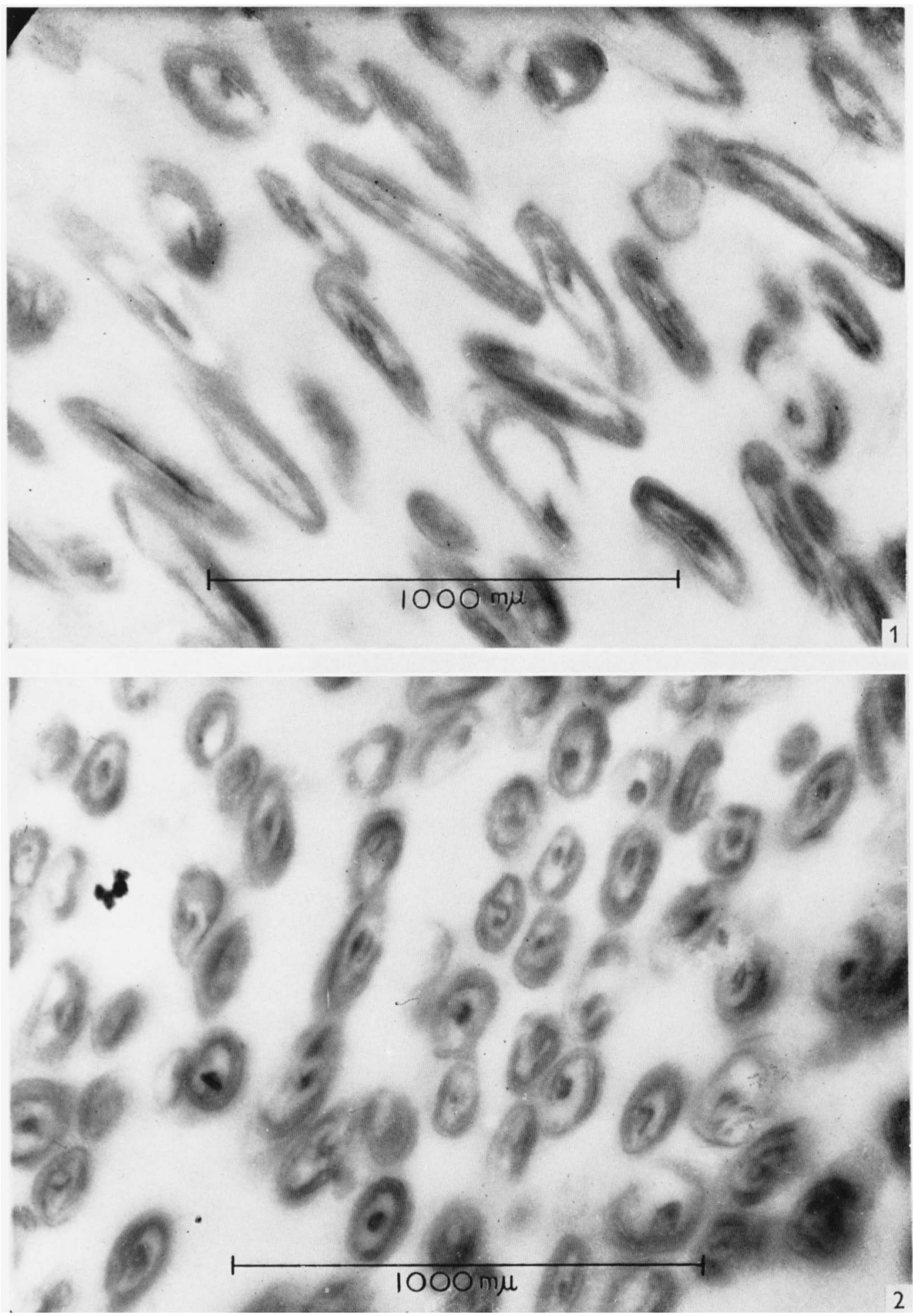

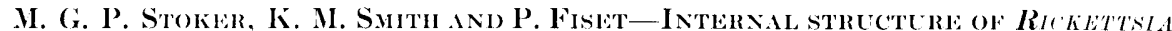
BURNETI. PLATL: 1 
Journal of General Microbiology, Vol. 15, No. 3

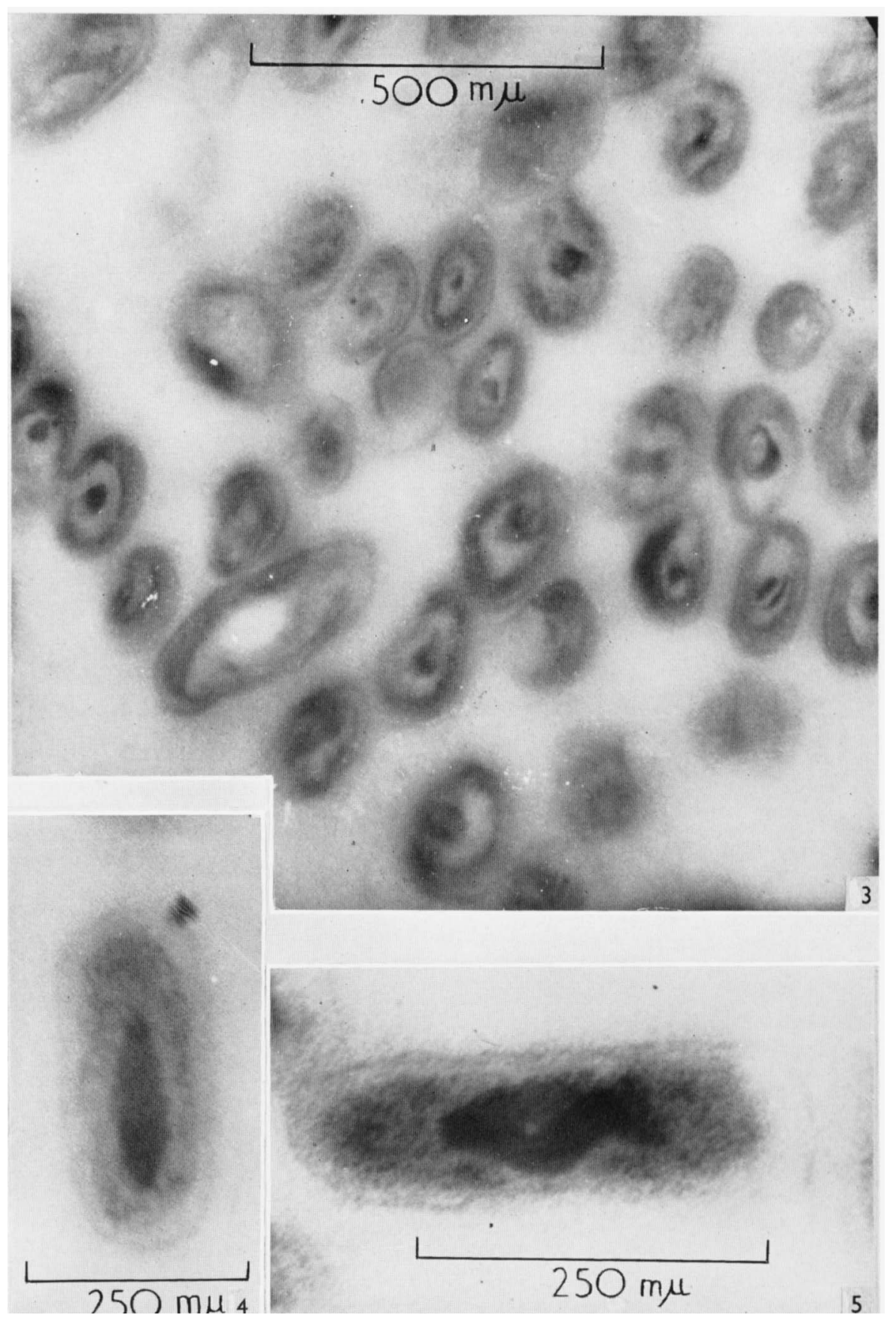

M. G. P. Stoker, K. M. SMith ANo P. Fislit-Internal structerlio of Rickettsia BURNeTit. Plate 2 
We wish to express our gratitude to Miss S. Vernon Smith, of the Agricultural Research Council Virus Research Unit, and Mr R. Horne, of the Cavendish Laboratory, for assistance with the electron micrographs. One of the authors (P. F.) is a Professional Training Fellow of the Department of Health and Welfare of the Province of Quebec.

\section{REFERENCES}

Birch-Anderson, A., Maaløe, O. \& Sjöstrand, F. S. (1953). High-resolution electron micrographs of sections of E. coli. Biochim. biophys. Acta, 12, 395.

Bradfield, J. R. G. (1954). Electron microscopic observations on bacterial nuclei. Nature, Lond. 173, 184.

Bradfield, J. R. G. (1956). Sixth Symp. Soc. gen. Microbiol. p. 296. Cambridge University Press.

Chapman, G. B. \& Hillier, J. (1953). Electron microscopy of ultra thin sections of bacteria. I. Cellular division in Bacillus cereus. J. Bact. 66, 362.

GaYLORd, W. H. (1954). Intracellular forms of meningopneumonitis virus. J. exp. Med. 100, 575.

Gaylord, W. H. \& Melnick, J. L. (1953). Intracellular forms of pox viruses as shown by the electron microscope (vaccinia, electromelia, molluscum contagiosum). J. exp. Med. 98, 157.

Kellenberger, E. \& RYter, A. (1955). Contribution a l'étude du noyau bactérien. Schweiz. Z. Path. 18, 1122.

MaAløe, O., Birch-Andersen, A. (1956). Sixth Symp. Soc. gen. Microbiol. p. 261. Cambridge University Press.

Morgan, C., Ellison, S. A., Rose, H. M. \& Moore, D. H. (1954a). Structure and development of viruses as observed in the electron microscope. I. Herpes simplex virus. J. exp. Med. $100,195$.

Morgan, C., Ellison, S. A., Rose, H. M. \& Moore, D. H. (1954,b). Structure and development of viruses observed in the electron microscope. II. Vaccinia and fowl pox viruses. J. exp. Med. 100, 301.

Sмiтн, J. D. \& Sтокеr, M. G. P. (1951). The nucleic acids of Rickettsia burneti. Brit. J. exp. Path. 32, 433.

Stoker, M. G. P. (1950). Q fever in Great Britain. The causative agent. Lancet, ii, 616.

Stoker, M. G. P. (1953). Variation in complement-fixing activity of Rickettsia burnetii during egg adaptation. J. Hyg., Camb. 51, 311.

\section{EXPLANATION OF PLATES}

\section{Plate 1}

Fig. 1. Electron micrograph of purified suspension of Rickettsia burnetii with organisms sectioned longitudinally. $(\times \mathbf{7 2 , 0 0 0}$.

Fig. 2. Electron micrograph of purified suspension of Rickettsia burnetii with organisms sectioned transversely. $(\times \mathbf{7 2 , 0 0 0})$

Plate 2

Fig. 3. Electron micrograph of purified suspension of Rickettsia burnetii with organisms sectioned transversely. $(\times 96,000)$

Fig. 4. Electron micrograph of single rickettsia sectioned longitudinally. $(\times 120,000$. $)$

Fig. 5. Electron micrograph of single rickettsia, sectioned longitudinally. $(\times 192,000$. 